\title{
PENGARUH LEVERAGE, WORKING CAPITAL TURNOVER, DAN NET PROFIT MARGIN TERHADAP PROFITABILITAS PADA PERUSAHAAN BUMN YANG TERDAFTAR DI BURSA EFEK INDONESIA
}

\author{
${ }^{1}$ Cut Riska Jafira , ${ }^{2}$ Sri Elviani , ${ }^{3}$ Yusrita, ${ }^{4}$ Ramadona Simbolon \\ Universitas Islam Sumatera Utara \\ cutriskajafira1208@gmail.com, srielviani@fe.uisu.ac.id,yusrita@fe.uisu.ac.id,ramadona.simbolon@fe.uisu.ac.id
}

\begin{abstract}
The objectives in this study are whether Debt to equity ratio, Debt to assets ratio, Working capital turnover and Net profit margin simultaneously affect the Profitability projected with Return on Assets on state-owned companies listed on the Indonesia Stock Exchange. In this study, there is an influence of Debt to equity ratio, Debt to assets ratio, Working capital turnover and Net profit margin on Profitability which is projected with Return on Assets on state-owned companies listed on the Indonesia Stock Exchange.The population in this study is state-owned companies listed on the Indonesia Stock Exchange in 2017-2019. The selection of samples in this research was conducted using purposive sampling method, which became a sample of 16 companies. The data type in this study is secondary data. The analysis method used is descriptive statistics. The results concluded that the impartiality of theDebt to assets ratio andNet profit margins had an impact on theprofitability of theDebt to equity ratio and working capital turnover did not affect the Simultaneous Productability (Test $F$ ) that the overall independent variable significantly affected profitability in state-owned companies listed on the Indonesia Stock Exchange.
\end{abstract}

Keywords : Leverage, Debt to Equity Ratio, Debt to Assets Ratio, Working Capital Turnover,Net Profit Margin, Profitabilitas dan Return on Assets.

ABSTRAK : Tujuan dalam penelitian ini yaitu apakah Debt to equity ratio, Debt to assets ratio, Working capital turnover dan Net profit margin secara simultan berpengaruh terhadap Profitabilitasyang diproksikan dengan Return on Assetspada perusahaan BUMN yang terdaftar di Bursa Efek Indonesia. Dalam penelitian ini bertujuan apakah ada pengaruh Debt to equity ratio, Debt to assets ratio, Working capital turnover dan Net profit margin terhadap Profitabilitasyang diproksikan dengan Return on Assetspada perusahaan BUMN yang terdaftar di Bursa Efek Indonesia.Populasi dalam penelitian ini adalah perusahaan BUMN yang terdaftar di Bursa Efek Indonesia tahun 2017-2019. Pemilihan sampel dalampenelitianinidilakukan dengan menggunakan metode purposive sampling, yang menjadi sampel sebanyak 16 perusahaan. Jenis data dalam penelitian ini adalah data sekunder. Metode analisis yang digunakan adalah Statistik deskriptif. Hasil penelitian menyimpulkanbahwasecaraparsialDebt to assets ratio danNet profit marginberpengaruhterhadapProfitabilitassedangkanDebt to equity ratiodan Working capital turnovertidakberpengaruhterhadapProfitabilitas Secara simultan (Uji F) bahwa keseluruhan variabel independen berpengaruh secara signifikan terhadap Profitabilitaspada perusahaan BUMN yang terdaftar di Bursa Efek Indonesia.

Kata Kunci : Leverage, Debt to Equity Ratio, Debt to Assets Ratio, Working Capital Turnover,Net Profit Margin, Profitabilitas dan Return on Assets.

\section{PENDAHULUAN}

\section{I.1. Latar Belakang Masalah}

Perusahaan memiliki kemampuan untuk memperoleh laba dalam waktu yang telah ditentukan dan bisa diukur dengan cara melihat penggunaan aktivanya bagaimana agar terlihat produktif disitulah dapat menilai kemampuan suatu perusahaan Kinerja keuangan dikelola dengan baik akan menarik bagi para investor untuk percaya dan menginvestasikannya kepada perusahaan yang telah dipilihnya agar mendapatkan laba sesuai dengan visi misinya. Semakin tinggi tingkat profitabilitasnya maka semakin tinggi pula tingkat kemampuan perusahaan dalam menghasilkan laba. 
Profitabilitas dalam perusahaan bisa diukur dari margin laba bersih, rasio pengembalian atas investasi, dan rasio pengembalian atas ekuitas. Ada beberapa faktor yang dapat mempengaruhi tingkat profitabilitas suatu perusahaan yaitu asset, hutang, modal, pendapatan dan juga biaya. Apabila proporsi biaya perusahaan dan utang lebih banyak dibandingkan dengan modal sendiri, maka profitabilitasnya akan rendah. Rasio leverage dapat digambarkan sebagai tingkat kemampuan suatu perusahaan dalam menggunakan aktivanya untuk meningkatkan keuntungan bagi para investor dan leverage juga dapat diartikan sebagai tingkat penggunaan kewajiban dalam sumber pembiayaan perusahaan.

Alasan peneliti mengambil judul ini karena dari berbagai penelitian sebelumnya juga telah melaporkan hasil dari penelitian mereka yang tidak konsisten sehingga perlu dilakukannya penelitain Kembali tentang Rasio Leverage, Working Capital Turnover dan Net Profit Margin terhadap Profitabilitas

\subsection{Batasan Masalah}

Dalam memfokuskan penelitian ini agar masalah yang diteliti memiliki arah yang jelas. Maka peneliti memberikan beberapa Batasan masalah yaitu Perusahaan yang dipilih untuk diteliti merupakan perusahaan BUMN yang terdaftar di BEI periode 2017-2019 dan penelitian ini menggunakan profitabilitas sebagai variable dependen yang diproksikan dengan Return on Assets (ROA) dan variable independent yaitu leverage yang diproksikan dengan Debt to Equity Ratio (DER) dan Debt to Assets Ratio (DAR), variable selanjutnya Working Capital Turnover (WCT) dan Net Profit Margin (NPM).

\subsection{Rumusan Masalah}

1) Apakah DER berpengaruh terhadap profitabilitas pada perusahaan yang terdaftar BUMN di BEI?

2) Apakah DAR berpengaruh terhadap profitabilitas pada perusahaan yang terdaftar BUMN di BEI?

3) Apakah WCT berpengaruh terhadap profitabilitas pada perusahaan BUMN yang terdaftar di BEI?

4) Apakah NPM berpengaruh terhadap profitabilitas pada perusahaan BUMN yang terdaftar di BEI?
5) Apakah DER, DAR, WCT dan NPM berpengaruh terhadap profitabilitas pada perusahaan BUMN yang terdaftar di BEI ?

\section{I.4. Manfaat penelitian}

Adapun manfaat penelitian yang dilakukan yaitu Bagi instansi, sebagai bahan masukan bagi manajemen perusahaan BUMN yang terdaftar di BEI dalam mengambil keputusan tentang peningkatan atau penurunan leverage, WCT, dan NPM agar lebih efektif dan efisien, Bagi penulis, menambah pengetahuan tentang rasio leverage, WCT dan NPM serta kaitannya dengan profitabilitas dan Bagi pihak lain, sebagai acuan dalam penelitian mengenai objek masalah yang sama dimasa yang akan datang.

\section{LANDASAN TEORI \\ 2.1. Analisis rasio keuangan}

Untuk melihat kinerja suatu perusahaan dapat diukur dengan menggunakan beberapa jenis rasio keuangan. Setiap jenis rasio yang digunakan mempunyai fungsi dan tujuannya masing-masing yang kemudian memiliki hasil dari rasio yang diukur sehingga menjadi berarti bagi pengambilan keputusan. Menurut Kasmir (2014:106) jenis-jenis rasio keuangan adalah sebagai berikut : Rasio Likuiditas, Rasio Solvabilitas, Rasio Aktivitas, Rasio Rentabilitas/Profitabilitas, Rasio Pertumbuhan dan Rasio Penilaian.

Analisis rasio keuangan merupakah salah satu teknik yang digunakan perusahaan untuk menganalisis laporan keuangan dalam menilai prospek kinerja keuangan perusahaan tersebut dalam mengaitkan segala bentuk perkiraan yang terdapat dalam laporan keuangan seperti bentuk rasio keuangan yang akan memberikan informasi kepada si analisis mengenai posisi keuangan atau keadaan keuangan perusahaan tersebut.

Teknik Analisis Rasio Keuangan ada beberapa cara menurut Farah Mergaretha dalam fahmi (2014:59) diantaranya yaitu :

1) Analisis horizontal (trend analisist) bertujuan untuk melihat trend dari rasio perusahaan dalam jangka waktu tertentu dengan menggunakan perbandingan antara rasio keuangan perusahaan dari tahun sebelumnya.

2) Analisis vertikal, yaitu merupakan perbandingan antara rasio yang sejenis dari perusahaan lain yang sebidang dengan data rasio keuangan perusahaan 


\subsection{Rasio Profitabilitas}

Menurut Sartono (2012:122) rasio profitabilitas merupakan alat ukur untuk melihat seberapa mampu perusahaan dalam menghasilkan laba yang berkaitan dengan kegiatan penjualan, total aset ataupun modal sendri. Rasio yang digunakan dalam penelitian ini adalah Return on Assets (ROA) sebagai proksi dari variabel Profitabilitas dan Net Profit Margin (NPM) yang digunakan sebagai variabel independepen. Alasan penulis menggunakan return on assets karena ROA dapat menunjukkan seberapa besar kemampuan yang dimiliki oleh perusahaan dalam memperoleh laba menurut tingkat aktiva tertentu.

1. Return on Assets (ROA) digunakan untuk mengukur seberapa mampu suatu perusahaan dalam memperoleh laba yang berasal dari aktiva. Rumus dari Return on Assets adalah sebagai berikut :

$$
\text { ROA }=\frac{\text { Laba Bersih Setelah Pajak }}{\text { Total Aktiva }}
$$

2. Net Profit Margin (NPM) merupakan perbandingan antara jumlah laba bersih dengan total penjualan bersih perusahaan. Rumus Net Profit Margin adalah sebagai berikut :

$$
\mathrm{NPM}=\frac{\text { Laba Bersih Setelah Pajak }}{\text { Penjualan Bersih }}
$$

\subsection{Leverage}

Menurut Kasmir (2010:158) leverage dapat menggambarkan besarnya modal pribadi yang dijadikan jaminan hutangnya. Rasio Leverage diartikan sebagai gambaran oleh perusahaan untuk mengukur tingkat kemampuan aktiva yang dimiliki perusahaan dalam meningkatkan penghasilan bagi para investor, atau dengan arti lain rasio leverage dapat berfungsi sebagai tolak ukur tingkat kewajiban sebagai dasar sumber pembiayaan perusahaan.

\subsection{Debt to Equity Ratio (DER)}

Semakin tinggi tingkat persentase DER maka akan semakin tidak baik kondisi suatu perusahaan dikarenakan tidak memungkinkan bank menutupi semua hutang yang dimiliki perusahaan hanya dengan mengandalkan modalnya. Rumusnya yaitu:

$$
\text { DER }=\frac{\text { Total Hutang }}{\text { Total Ekuitas }}
$$

\subsection{Debt to Assets Ratio (DAR)}

Ratio ini dapat dikatakan juga sebagai rasio hutang yaitu variabel yang menggambarkan seberapa banyak proporsi dari aktiva yang menjadi sumber pendanaannya berasalh dari pinjaman atau kredit. Debt to Assets Ratio adalah rasio hutang yang digunakan untuk menilai dan mengukur perbandingan antara total hutang dengan total aktiva menurut Kasmir (2010:156). Secara teoritis, jika perusahaan dilikuidasi masih mampu untuk menutupi hutang yang dimilikinya dengan aktiva. Rumus yang digunakan untuk mencari DAR adalah sebagai berikut:

$$
\text { DAR }=\frac{\text { Total Hutang }}{\text { Total Assets }}
$$

\subsection{Perputaran Modal Kerja}

Perputaran modal kerja (working capital turnover) merupakan rasio yang dapat digunakan untuk menggambarkan dan mengukur tingkat keefektifan modal kerja suatu perusahaan dalam jangka waktu tertentu. Modal kerja yang dimiliki suatu perusahaan akan selalu mengalami perputaran dalam setiap opeasi perusahaan. Metode perputaran modal (turnover) dipilih dalam penelitian ini peneliti ini, karena dalam metode ini menggunakan laporan keuangan perusahaan untuk menganalisi dan sebagai tolak ukurnya. Riyanto (2010:62) telah membuat rumus untuk mengukur working capital turnover yaitu sebagai berikut:

$$
\mathrm{WCT}=\frac{\text { Pendapatan Bersih }}{\text { Aktiva Lancar }- \text { Hutang Lancar }}
$$

\subsection{Kerangka Konseptual}

Berdasarkan latar belakang permasalahan dan landasan teori yang telah dipaparkan sebelumya maka kerangka konseptual penelitian ini dapat digambarkan sebagai berikut : 


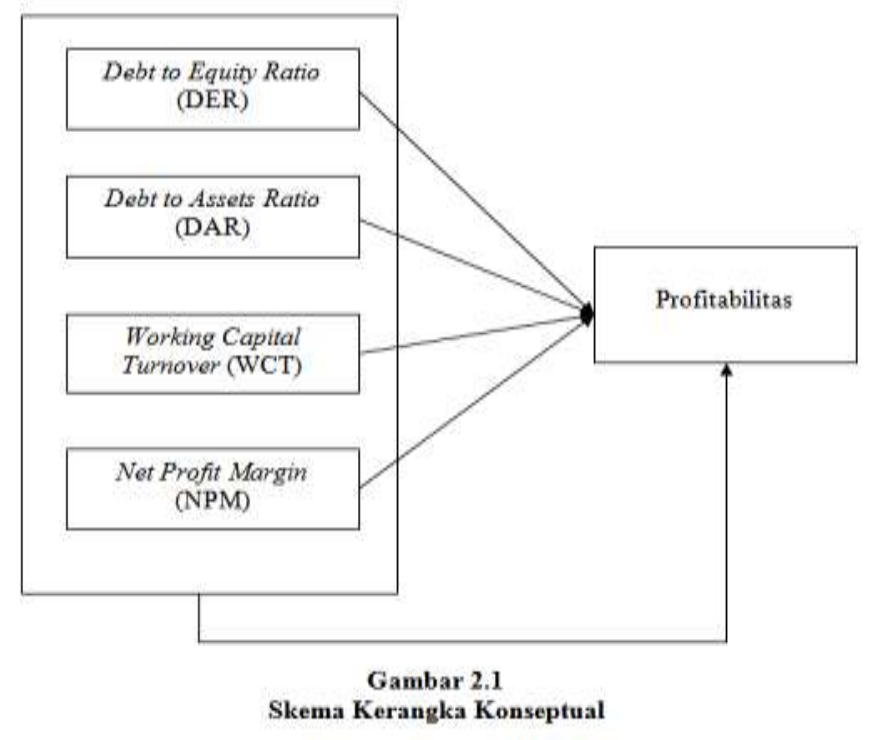

Gambar 1. Kerangka Konseptual

\section{METODE PENELITIAN}

\subsection{Jenis dan Sumber Data}

Jenis Data yang digunakan merupakan data sekunder yang dimana telah diolah lebih rinci dan disajikan oleh pihak pengumpul maupun pihak lain. Data yang diperoleh adalah data time series tahun 2017-2019, dimana data diperoleh dari situs resmi www.idx.co.id. Dalam penelitian ini populasi yang digunakan adalah perusahaan BUMN yang terdaftar di Bursa Efek Indonesia. Dalam penelitian ini sampel yang digunakan adalah perusahaan BUMN yang terdaftar di Bursa Efek Indonesia tahun 2017-2019.Variabel dependen di dalam penelitian ini adalah Profitabilitas yang dapat dilihat dari Return on Assets sebagai indikatornya. Return on Assets dapat dilihat dari laba bersih dengan total asset. Variabel dependen yang digunakan dalam penelitian ini untuk mengetahui variabel Leverage adalah Debt to Equity Ratio dan Debt to Assets. Dan variabel lainnya yaitu Work Capital Turnover dan Net Profit Margin

\subsection{Teknik Pengumpulan Data}

Teknik pengumpulan data yang dipakai dalam penelitian ini adalah studi dokumentasi yang mengumpulkan data dari laporan keuangan 2017-2019 perusahaan BUMN yang terdaftar di BEI.

\subsection{Teknik Analisis Data}

Teknik analisis data yang digunakan peneliti adalah Teknik Analisis Rasio Keuangan, kemudian dilanjutkan dengan Analisis Deskriptif dalam menguraikan hasil dari analisis tersebut. Analisis deskriptif merupakan suatu metode penganalisaan yang bersifat memberikan penjelasan tentang suatu hal permasalahan berdasarkan data - data, angka angka dan keterangan - keterangan yang kemudian dipaparkan secara jelas dan sistematis, dapat diklasifikasi dan dianalisis sehingga diperoleh gambaran yang jelas tentang masalah apa yang akan diteliti.

Metode analisis yang digunakan dalam penelitian ini adalah metode analisis statistik dan menggunakan software SPSS v 20.0. Hal yang perlu diperhatikan sebelum data dianalisis terlebih dahulu adalah sebagai berikut :

\subsubsection{Statistik Deskriptif}

Statistik deskriptif merupakan metode statistik yang berfungsi untuk menjelaskan atau menggambarkan data yang telah didapat untuk menjadi sebuah informasi (Suharyadi, 2007:10).

\subsubsection{Uji Asumsi Klasik}

Uji asumsi klasik dapat dilakukan untuk memberi tau informasi bahwa sampel yang akan diuji atau di teliti terhindar dari gangguan normalitas, multikolinieritas, autokorelasi, dan heteroskedastisitas. Maka dari itu uji yang akan digunakan dalam penelitian ini adalah uji normalitas, uji multikolonieritas, uji autokorelasi, dan uji heteroskedatisitas.

\subsubsection{Uji Normalitas Data}

Menurut (Ghozali, 2013) uji normalitas memiliki tujuan untuk menguji apakah dalam model regresi, variabel pengganggu atau residul memiliki distribusi normal. 


\subsubsection{Uji Multikolinieritas}

Uji multikolinieritas digunakan untuk membuktikan antara dua variabel independen atau lainnya ada atau tidaknya hubungan (Ghozali, 2013). \Model pengujian ini dengan melihat nilai variance inflation factor (VIF). Jika nilai VIF>10 maka menunjukkan adanya multikolinieritas.

\subsubsection{Uji Autokorelasi}

Uji Autokorelasi dimaksudnya dengan tujuan untuk menguji residual dari model regresi dalam menentukan korelasi antara pengganggu pada periode $t$ dengan kesalahan pengganggu pada periode t-1. Model regresi ini dapat dinilai baik apabila tidak ada terjadinya autokorelasi. Untuk melihat ada atau tidaknya autokorelasi dalam model regresi ini dapat dilihat dari besarnya nilai D-W (Durbin Watson

\subsubsection{Uji Heterokedastisitas}

Uji heterokedastisitas dimaksudnya dengan tujuan untuk mengetahui apakah terjadi ketidaksamaan varians pada residual dari model regresi. Model regresi yang homoskedastisitas atau terjadi heteroskedastisitas merupakan model regresi yang baik (Ghozali,2013).

\subsubsection{Uji Parsial (Uji t)}

Untuk mengukur masing-masing variable seberapa besar pengaruhnya antara satu variable dengan yang lain maka dapat menggunakan uji t. Menggunakan uji masing-masing koefisien regresi variabel bebas apakah memiliki pengaruh yang bermakna atau tidak terhadap variabel terikat.

1) $H_{0}$ diterima dan $H_{a}$ ditolak jika $t_{\text {hitung }}<t_{\text {tabel }}$ untuk $a=0,05$

2) $H_{0}$ ditolak dan $H_{a}$ diterima jika $t_{\text {hitung }}>t_{\text {tabel }}$ untuk $\mathrm{a}=0,05$

\subsubsection{Uji F}

Untuk mengetahui koefisien regresi secara simultan maka dapat menggunakan Uji. Pengujian ini dapat dihitung untuk mengetahui seberapa besar pengaruhnya dari seluruh variabel independen yang terdapat di dalam model secara bersama-sama (simultan) terhadap variabel dependen. Uji $\mathrm{F}$ dalam penelitian ini digunakan untuk menguji signifikasi pengaruh DER, DAR, WCT, dan NPM terhadap Profitabilitas yang diproksikan dengan ROA.

1) $\mathrm{H}_{0}$ ditolak jika $\mathrm{F}_{\text {hitung }}>\mathrm{F}_{\text {tabel }}$ atau nilai sig < $\alpha$

2) $\mathrm{H}_{0}$ diterima jika $\mathrm{F}_{\text {hitung }}\left\langle\mathrm{F}_{\text {tabel }}\right.$ atau nilai sig $>$ $\alpha$

\subsubsection{Koefisien Determinasi $\left(\mathbf{R}^{2}\right)$}

Nilai dari koefisien deteminasi adalah aturan nol dan satu. Dalam menjelaskan variasi variabel dependen yang sangat terbatas maka dapat menunjukkan variabel-variabel independen dengan Nilai $\mathrm{R}^{2}$ yang lebih kecil. Untuk memprediksi variasi variabel dependen dengan memberikan semua informasi yang dibutuhkan maka nilai yang mendekati satu (Ghozali 2016:95).

\section{Hasil Penilitian}

\subsection{Analisis Statistik Deskriptif}

Table 1. Statistik Deskriptif Variabel Penelitian. Descriptive Statistics

\begin{tabular}{|l|r|r|r|r|r|}
\hline & \multicolumn{1}{|c|}{$\mathrm{N}$} & Minimum & Maximum & \multicolumn{1}{l|}{ Mean } & Std. Deviation \\
\hline DER & 48 &, 42 & 11,30 & 3,2492 & 2,74732 \\
DAR & 48 &, 29 &, 86 &, 6473 &, 17548 \\
WCT & 48 & $-198,52$ & 383,75 & 7,0857 & 63,89080 \\
NPM & 48 &, 01 &, 58 &, 1800 &, 16468 \\
ROA & 48 &, 00 &, 26 &, 0513 &, 05851 \\
Valid N (listwise) & 48 & & & & \\
Sumber : data yang diolah (2020) & & & & \\
\hline
\end{tabular}

Pada tabel 1 menunjukkan bahwa jumlah laporan tahunan perusahaan BUMN yang terdaftar di Bursa Efek Indonesia (BEI). data yang digunakan dalam penelitian ini adalah sebanyak 48 sampel data yang diambil dari 
Berdasarkan data tabel 5.1 dapat dijelaskan bahwa:

1) Debt to Equity Ratio, nilai minimumnya 0,42 dan nilai maksimumnya 11,30 dengan nilai rata-ratanya 3,2492 . Standar deviasi rasio ini adalah 2,74732. Jumlah data yang digunakan sebanyak 48.

2) Debt to Assests Ratio, nilai minimumnya 0,29 dan nilai maksimumnya 0,86 dengan nilai rata-ratanya 0,6473 . Standar deviasi rasio ini adalah 0,17548 . Jumlah data yang digunakan sebanyak 48 .

3) Working Capital Turnover, nilai minimumnya -198,52 dan nilai maksimumnya 383,75 dengan nilai rataratanya 7,0857 . Standar deviasi rasio ini adalah 63,89080 . Jumlah data yang digunakan sebanyak 48.

4) Net Profit Margin, nilai minimumnya 0,01 dan nilai maksimumnya 0,58 dengan nilai rata-ratanya 0,1800 . Standar deviasi rasio ini adalah 1,6468. Jumlah data yang digunakan sebanyak 48.

5) Profitabilitas (Y) dalam penelitian ini diukur dengan variabel Return on Assets. Minimum yang dimiliki sebesar 0,00 dan maksimumnya 0,26 dengan nilai rataratanya 0,513 . Standar deviasi rasio ini adalah sebesar 0,5851. Jumlah data yang digunakan sebanyak 48.

\section{Kesimpulan}

Berdasarkan dari hasil uji analisis dalam penelitian ini, maka dapat diambil kesimpulan bahwa :

1) Debt to Equity Ratio tidak berpengaruh terhadap Profitabilitas

2) Debt to Assets Ratio berpengaruh negatif dan signifikan terhadap Profitabilitas

3) Working Capital Turnover tidak berpengaruh terhadap Profitabilitas

4) Net Profit Margin berpengaruh positif dan signifikan terhadap Profitabilitas

5) Debt to Equity Ratio, Debt to Assets Ratio, Working Capital Turnover, Net Profit Margin berpengaruh positif signifikan terhadap Profitabilitas pada perusahaan BUMN yang terdaftar di Bursa Efek Indonesia (BEI).

\section{DAFTAR PUSTAKA}

Agus Sartono. 2014. Manajemen Keuangan

Teori dan Aplikasi. Edisi empat . Cetakan ke tujuh

Yogyakarta:Penerbit BPFE
Atmaja, Lukas Setia. (2008). Teori dan Prkatik Manajemen Keuangan. Yogyakarta:

Andi.

Bambang Riyanto. 2010. Dasar-Dasar Pembelanjaan Perusahaan, ed. 4, BPFEYOGYAKARTA.

Fahmi, Irham. (2012). Pengantar Pasar Modal. Bandung: Alfabeta.

Fahmi, Irham. (2014). Analisa Laporan Keuangan. Bandung: Alfabet.

Fariddan Siswanto. 2011. Analisis Laporan Keuangan. Jakarta: BumiAksara.

Ghozali, Imam. 2013. Aplikasi Analisis Multivarite dengan Program IBM SPSS 21. Semarang: Badan Penerbit Universitas Diponogoro, Semarang.

Ghozali, Imam. 2016. Aplikasi Analisis Multivariete Dengan Program IBM SPSS 23 (edisi 8). Cetakan ke VIII. Semarang: Badan Penerbit Universitas Diponegoro.

Gulo. 2010. Metodologi Penelitian.Jakarta: Grasindo.

Harahap, Sofian Safri, 2010. Analisis Krisis Atas Laporan Keuangan, Jakarta: Rajawali Persada.

Indriantoro, N, dan Supormo, B. 2014. Metodologi Penelitian Bisnis. Yogyakarta: PT BPFE.

Joel G. Siegel dan jae K. shim, kamus istilah Akuntansi (terjemah), (Jakarta:

Elek Media Komputindo, 1999). Dalam Fahmi, Irham. 2012. Analisis Laporan Keuangan. Bandung: Alfabeta cv.

Kasmir. 2010. Pengantar Manajemen Keuangan. Jakarta: Kencana Prenada Media Group.

Kasmir. 2013. "Analisis Laporan Keuangan". Edisi 1. Cetakan ke-6. Jakarta: Rajawali Pers.

Kamir, 2014. Analisis Laporan Keuangan, Edisi Pertama, Cetakan Ketujuh. Jakarta: Raja Grafindo Persada.

Margaretha, Farah. 2014. Dasar-dasar Manajemen Keuangan. Jakarta: PT Dian Rakyat

Munawir, S. 2014. Analisis Laporan Keuangan. Edisi Keempat. Yogyakarta:Liberty Yogyakarta.

Nugroho. 2010. Sistem Informasi Manajemen. Yogyakarta.

Rudianto. 2012. Pengantar Akuntansi. Adaptasi IFRS. Jakarta : Erlangga.

Sartono. 2012. Serba-Serbi Manajemen Bisnis. Yogyakarta: Grahalmu 
Subramanyam dan John J. Wild. 2012. Analisis Laporan Keuangan. Jakarta: Salemba Empat.

Sudana, I Made. 2011. Manajemen Keuangan Perusahaan Teori dan Praktik. Jakarta: Erlangga.

Sugiyono. 2011. Metode Penelitian Kuantitatif, Kualitatif dan R\&D. Bandung: Afabeta

Suharyadi. 2007. Statistika untuk Ekonomi dan Keuangan Modern edisi 2 jilid 1. Jakarta: Salemba Empat

Sutrisno. 2012. Manajemen Keuangan Teori, Konsep dan Aplikasi. Yogyakarta: EKONISIA.

https://britama.com/index.php/perusahaantercatat-di-bei/, https://www.sahamok.net/emiten/bumnpublik-bei/ 